\title{
Rate of Reduction of Silica in Slag by Carbon in Liquid Iron*
}

\author{
By Yasuji KAWAI,** Katsumi MORI,** and Mitsushi IGUCHI***
}

\begin{abstract}
Synopsis
The rate of reduction of silica in $\mathrm{CaO}-\mathrm{SiO}_{2}$ and $\mathrm{CaO}-\mathrm{Al}_{2} \mathrm{O}_{3}-\mathrm{SiO}_{2}$ slags by carbon dissolved in liquid iron was measured under various experimental conditions to examine effects of slag composition, temperature, atmosphere, and slag-graphite interfacial area.

Effect of slag composition was ascribed to the change in activity of silica. Apparent activation energies were about $100 \mathrm{kcal} / \mathrm{mol}$ for binary slags and 70 to $85 \mathrm{kcal} / \mathrm{mol}$ for ternary slags.

The rate of the reduction increased linearly with the ratio of slag-graphite to slag-metal interfacial area in the low ratio region. It was found from this result that the anodic reaction occurred at both slag-metal and slaggraphite interfaces, and that the interfacial reaction is the rate-determining step.

The rate of reduction in argon atmosphere was about twice as fast as that in $\mathrm{CO}$ atmosphere.
\end{abstract}

\section{Introduction}

The reduction of silica in slags to silicon by carbon dissolved in liquid iron is one of the most important problems in the blast furnace operation, because the degree of reduction not only determines the content of silicon in pig iron, but also it influences on the other slag-metal reactions such as the desulfurization and the reduction of manganese oxide.

Hitherto, the kinetic studies on this reaction have been made by many investigators ${ }^{1-6)}$ and various opinions have been proposed on the rate-determining step based on their experimental results. It seems that such a discrepancy of opinions may be ascribed to the difference in the experimental conditions and the experimental difficulties at high temperature. Recently M. Ohtani and coworkers ${ }^{6)}$ have proposed an application of the electrode kinetics to the study of the silicon transfer from slag to metal.

In order to derive the rate equation and to clarify the reaction mechanism, it seemed to be necessary to examine more throughly the relations between the rate and various factors. So in the present work, the effects of slag composition and the slag-graphite interfacial reaction on the rate of silica reduction were investigated to obtain the quantitative relationship between the rate and the activity of silica or the ratio of slag-graphite to slag-metal interfacial area. Also, the effect of the atmosphere on the rate was examined.

\section{Experimental Method}

The experimental apparatus is shown schematically in Fig. 1. A reaction tube is $55 \mathrm{~mm}$ in I.D. and $500 \mathrm{~mm}$ in length. A sampling hole and a gas inlet hole are attached to the upper sealing brass cap and a protection tube for a thermocouple and a gas outlet hole are attached to the lower cap.

A high frequency induction furnace $(15 \mathrm{~kW}, 200 \mathrm{kc})$ was used for heating. Temperature was measured by the $\mathrm{Pt}-6 \% \mathrm{Rh} / \mathrm{Pt}-6 \% \mathrm{Rh} / \mathrm{Pt}-30 \% \mathrm{Rh}$ thermocouple inserted into the crucible bottom and was held constant within $\pm 3^{\circ} \mathrm{C}$ by an automatic controller.

Iron-carbon alloys were prepared by melting electrolytic iron in a graphite crucible. Slags were synthesized by melting chemical reagents, such as silica, aluminium oxide and calcium carbonate in a graphite crucible. The chemical composition of synthetic slags is given in Table 1.

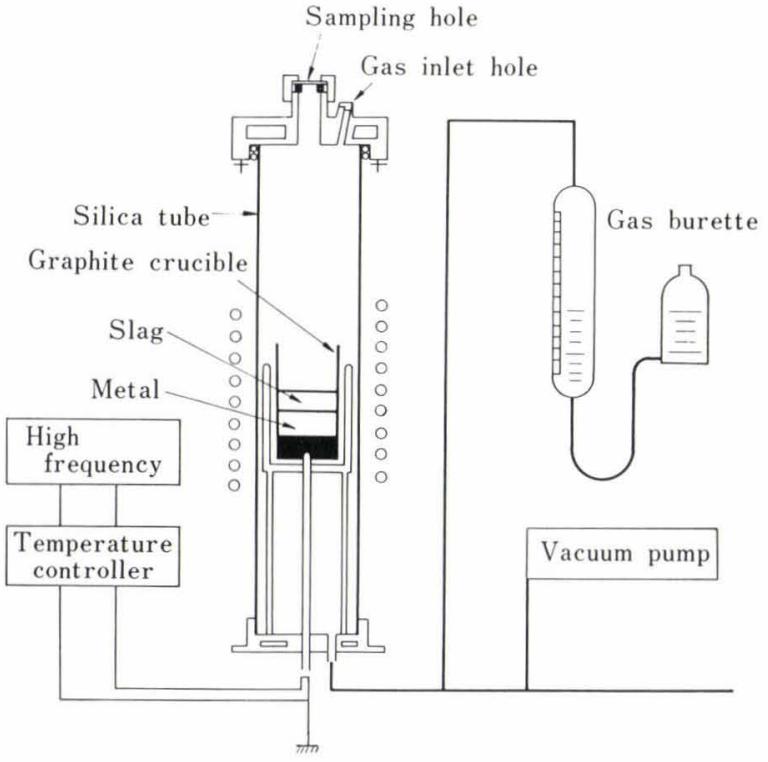

Fig. 1. Experimental apparatus

Table 1. Composition of slag

\begin{tabular}{c|ccccc}
\hline Slag & $\begin{array}{c}\mathrm{CaO} \\
(\%)\end{array}$ & $\begin{array}{c}\mathrm{SiO}_{2} \\
(\%)\end{array}$ & $\begin{array}{c}\mathrm{Al}_{2} \mathrm{O}_{3} \\
(\%)\end{array}$ & $\begin{array}{c}\mathcal{N}_{\mathrm{SiO}_{2}} \\
a_{\mathrm{SiO}_{2}}\end{array}$ \\
\hline$A$ & $35-37$ & $65-63$ & - & 0.62 & 0.88 \\
$D$ & 40 & 60 & - & 0.58 & 0.83 \\
$E$ & 45 & 55 & - & 0.53 & 0.58 \\
$F$ & 50 & 50 & - & 0.48 & 0.34 \\
$G$ & 55 & 45 & - & 0.43 & 0.14 \\
$C$ & 26 & 70 & 4 & 0.70 & 0.95 \\
$K$ & 40 & 50 & 10 & 0.51 & 0.40 \\
$I$ & 30 & 50 & 20 & 0.53 & 0.45 \\
$J$ & 40 & 40 & 20 & 0.43 & 0.21 \\
$L$ & 50 & 40 & 10 & 0.40 & 0.13 \\
$M$ & 50 & 35 & 15 & 0.36 & 0.05 \\
\hline
\end{tabular}

* Originally published in Tetsu-to-Hagané, 56 (1970), 1447, in Japanese. English version received July 30 , 1971.

** Department of Iron and Steel Metallurgy, Faculty of Engineering, Kyushu University, Hakozaki, Fukuoka 812.

*** Kakogawa Works, Kobe Steel Ltd., Kakogawa 675-01. 
Metal and slag were heated under evacuating in a graphite crucible, the profile of which is shown in Fig. 2. Before melting of metal the reaction tube was filled with carbon monoxide gas at 1 atm. After holding about $20 \mathrm{~min}$ at the experimental temperature, the first metal sample was taken by suctioning it into a silica tube, and then the subsequent samples were taken at predetermined intervals. Their silicon contents were determined by the gravimetric chemical analysis. At the same time the volume of carbon monoxide gas evolved was measured by a gas burette to check the reaction. The rate of reduction of silica was calculated from the increase of the silicon content of iron.

\section{Experimental Results}

\section{Effect of Slag Composition and Temperature}

It is considered that the dependence of the silicon transfer rate on the activity of silica is different according to the different rate-determining steps. Therefore, the examination of the effect of slag composition on the rate will give a valuable information for the determination of the rate-determining step.

The rates were measured for various slags under $\mathrm{CO}$ atmosphere at temperatures from $1500^{\circ}$ to $1650^{\circ} \mathrm{C}$ in graphite crucible shown in Fig. 2 (a). Charges were $100 \mathrm{~g}$ of carbon-saturated iron and $20 \mathrm{~g}$ of slags.

Some results are illustrated in Figs. 3 and 4 as plots of the weight of silicon transferred to iron versus time. These show a linear relation for all runs and the weight of silicon transferred $\lrcorner \mathrm{Si}$ is given by

$$
\lrcorner \mathrm{Si}=R \cdot t
$$

where $R$ is the slope of the line i.e. the apparent rate coefficient and $t$ the reduction time. The values of $R$ calculated by the least square method are summarized in Tables 2 and 3.

In Fig. 5, $R$ are plotted against the activity of silica in slag, which was estimated from the data by R. H. Rein and J. Chipman. ${ }^{7)}$ It is found that the experimental points are on straight lines independent of slag composition over the whole composition range of slags

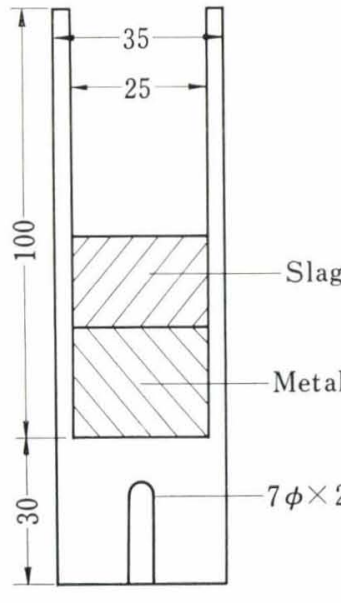

(a)

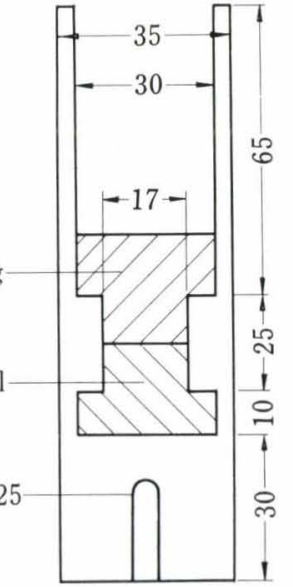

(b)
Fig. 2. Graphite crucible arrangement (mm)

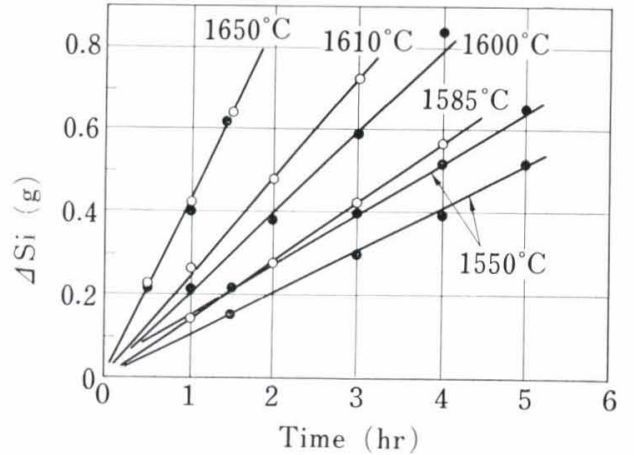

Fig. 3. Silicon transferred from slag to metal (slag $A$ )

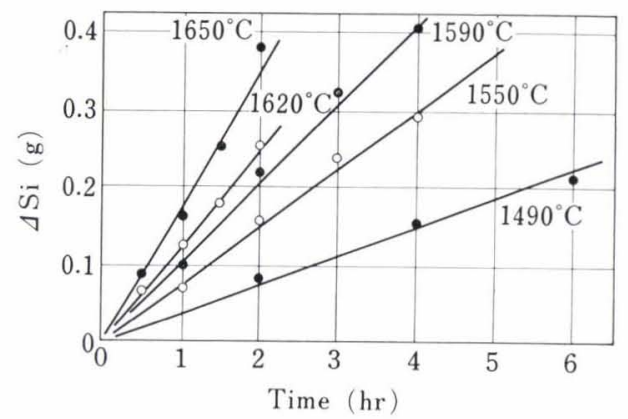

Fig. 4. Silicon transferred from slag to metal (slag $I$ )

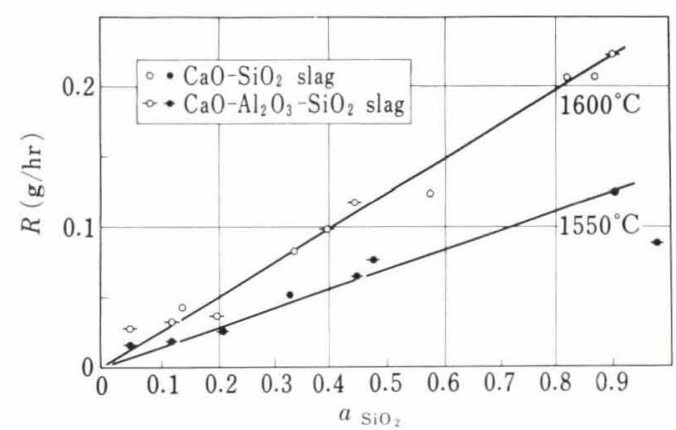

Fig. 5. Relation between apparent rate constant and activity of silica

Table 2. Rate of reduction of silica in $\mathrm{CaO}-\mathrm{SiO}_{2}$ slags

\begin{tabular}{|c|c|c|c|c|}
\hline Slag & Temp. $\left({ }^{\circ} \mathrm{C}\right)$ & {$[\% \mathrm{Si}]_{\text {initial }}$} & $R(\mathrm{~g} / \mathrm{hr})$ & $a_{\mathrm{SiO}_{2}}$ \\
\hline \multirow{7}{*}{$A$} & 1550 & 0.04 & 0.122 & \multirow[t]{3}{*}{0.91} \\
\hline & 1550 & 0.08 & 0.100 & \\
\hline & 1585 & 0.12 & 0.141 & \\
\hline & 1600 & 0.19 & 0.204 & \multirow[t]{4}{*}{0.88} \\
\hline & 1610 & 0.12 & 0.236 & \\
\hline & 1650 & 0.14 & 0.423 & \\
\hline & 1650 & 0.20 & 0.427 & \\
\hline$D$ & 1600 & 0.29 & 0.203 & 0.83 \\
\hline$E$ & 1600 & 0.29 & 0.122 & 0.58 \\
\hline \multirow{5}{*}{$F$} & 1560 & 0.11 & 0.0491 & \multirow[t]{2}{*}{0.33} \\
\hline & 1560 & 0.27 & 0.0421 & \\
\hline & 1600 & 0.17 & 0.0828 & \multirow[t]{3}{*}{0.34} \\
\hline & 1600 & 0.19 & 0.0798 & \\
\hline & 1640 & 0.25 & 0.141 & \\
\hline$G$ & 1640 & 0.19 & 0.067 & 0.14 \\
\hline
\end{tabular}


used in the present experiment, although the scattering of data was relatively large in the range $a_{\mathrm{SiO}_{2}}<0.1$. This fact shows that the reaction rate is given by the first order equation with respect to the activity of silica and the effect of slag composition can be explained by the variation of the activity of silica in slag.

The influence of temperature on the rate is shown in Figs. 6 and 7. The apparent activation energies are given in Table 4. In $\mathrm{CaO}-\mathrm{SiO}_{2}$ slags they were nearly constant $(100 \mathrm{kcal} / \mathrm{mol})$, but in $\mathrm{CaO}-\mathrm{Al}_{2} \mathrm{O}_{3}-\mathrm{SiO}_{2}$ slags they slightly varied from 70 to $85 \mathrm{kcal} / \mathrm{mol}$ with slag composition.

If the over-all reaction may be expressed as follows:

$$
\left(\mathrm{SiO}_{2}\right)+2 \underline{\mathrm{C}}=\underline{\mathrm{Si}}+2 \mathrm{CO}(\mathrm{g})
$$

two moles of $\mathrm{CO}$ gas must be evolved by the transfer of one mole of silicon from slag to iron. In Fig. 8 the volume of $\mathrm{CO}$ gas evolved is shown together with that calculated from the weight of silicon transferred into iron. It was found that at low activity of silica such as slag $F$ both lines agreed within an analytical error, but at high activity of silica such as slag $A \mathrm{CO}$

Table 3. Rate of reduction of silica in $\mathrm{CaO}-\mathrm{Al}_{2} \mathrm{O}_{3}-\mathrm{SiO}_{2}$ slags

\begin{tabular}{|c|c|c|c|c|}
\hline Slag & Temp. $\left({ }^{\circ} \mathrm{C}\right)$ & {$[\% \mathrm{Si}]_{\text {initial }}$} & $R(\mathrm{~g} / \mathrm{hr})$ & $a_{\mathrm{SiO}_{2}}$ \\
\hline \multirow{6}{*}{$C$} & 1500 & 0.30 & 0.0584 & \multirow{3}{*}{0.95} \\
\hline & 1550 & 0.14 & 0.0813 & \\
\hline & 1550 & 0.14 & 0.0907 & \\
\hline & 1600 & 0.11 & 0.205 & 0.91 \\
\hline & 1600 & 0.09 & 0.235 & \\
\hline & 1650 & 0.04 & 0.412 & \\
\hline \multirow{5}{*}{$\kappa$} & 1510 & 0.01 & 0.0432 & \multirow{5}{*}{$\begin{array}{l}0.45 \\
0.40\end{array}$} \\
\hline & 1530 & 0.17 & 0.0414 & \\
\hline & 1550 & 0.17 & 0.0642 & \\
\hline & 1600 & 0.11 & 0.0902 & \\
\hline & 1630 & 0.12 & 0.164 & \\
\hline \multirow{7}{*}{$I$} & 1490 & 0.07 & 0.0317 & \multirow{3}{*}{0.48} \\
\hline & 1550 & 0.18 & 0.0754 & \\
\hline & 1550 & 0.08 & 0.0752 & \\
\hline & 1590 & 0.13 & 0.1028 & 0.45 \\
\hline & 1610 & 0.17 & 0.120 & \\
\hline & 1620 & 0.13 & 0.123 & \\
\hline & 1650 & 0.07 & 0.184 & \\
\hline \multirow{5}{*}{$J$} & 1500 & 0.13 & 0.0142 & \multirow{5}{*}{0.21} \\
\hline & 1560 & 0.12 & 0.0274 & \\
\hline & 1570 & 0.13 & 0.0279 & \\
\hline & 1600 & 0.09 & 0.0359 & \\
\hline & 1665 & 0.13 & 0.0864 & \\
\hline \multirow{5}{*}{$L$} & 1560 & 0.09 & 0.0198 & \multirow{5}{*}{0.13} \\
\hline & 1610 & 0.01 & 0.0389 & \\
\hline & 1640 & 0.08 & 0.0534 & \\
\hline & 1650 & 0.03 & 0.0659 & \\
\hline & 1670 & 0.04 & 0.0682 & \\
\hline \multirow{2}{*}{$M$} & 1550 & 0.02 & 0.0142 & \multirow[b]{2}{*}{0.05} \\
\hline & 1600 & 0.04 & 0.0273 & \\
\hline
\end{tabular}

gas evolved more than that calculated from silicon transfer with increasing temperature. This may be caused by the following side reaction:

$$
\left(\mathrm{SiO}_{2}\right)+\underline{\mathrm{C}}=\mathrm{SiO}(\mathrm{g})+\mathrm{CO}(\mathrm{g}) .
$$

\section{Effect of Slag-Graphite Interface}

M. Grimble et al.5) and M. Ohtani et al. ${ }^{6)}$ pointed out that when a graphite crucible was used, the reduc-

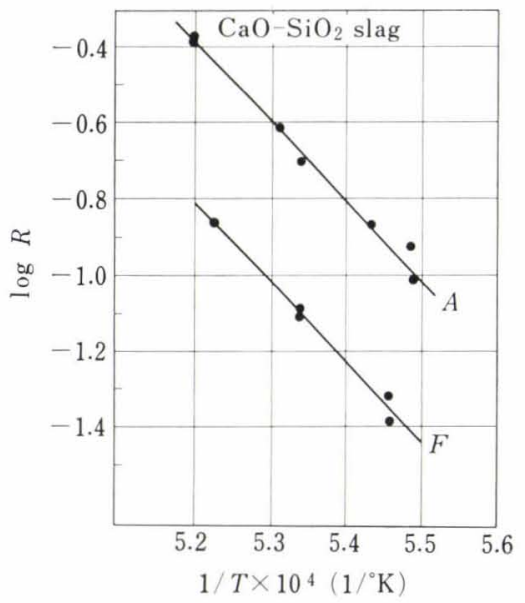

Fig. 6. Effect of temperature on rate constant

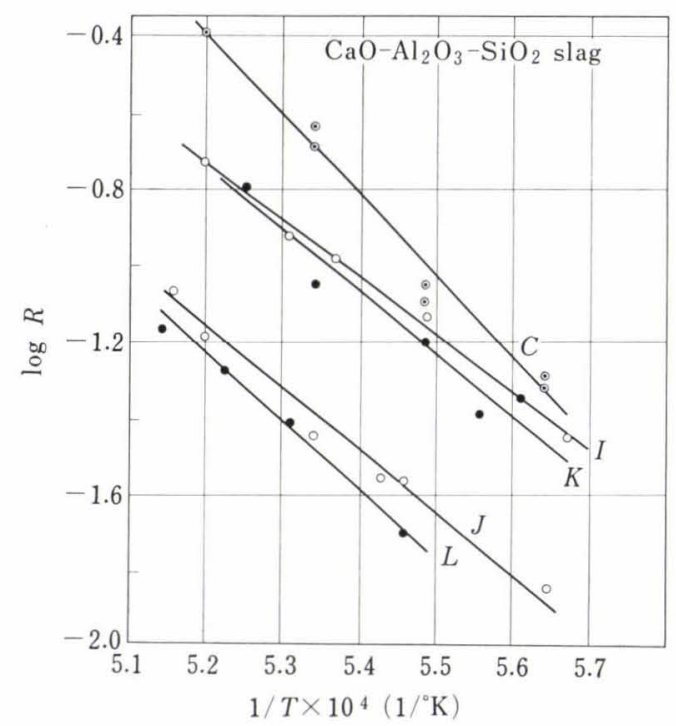

Fig. 7. Effect of temperature on rate constant

Table 4. Apparent activation energies of silica reduction $(\mathrm{kcal} / \mathrm{mol})$

\begin{tabular}{c|ccc}
\hline Atmosphere & CO & Argon & CO \\
\hline Slag weight $(\mathrm{g})$ & 20 & 20 & 40 \\
\hline Slag $A$ & $96 \pm 6$ & - & - \\
Slag $F$ & $97 \pm 4$ & $75 \pm 2$ & 100 \\
Slag $C$ & $98 \pm 5$ & - & - \\
Slag $K$ & $76 \pm 10$ & $89 \pm 4$ & 75 \\
Slag $I$ & $69 \pm 4$ & $77 \pm 3$ & - \\
Slag $J$ & $73 \pm 4$ & - & - \\
Slag $L$ & $83 \pm 5$ & - & \\
\end{tabular}


tion rate of silica increased with the increase of slaggraphite interfacial area due to local cell action.

To check this, the effect of slag-graphite interface was examined in the present work. The experiments were carried out at different ratios of slag-graphite to slag-metal interfacial area by varying slag weight or by using two kinds of graphite crucibles shown in Fig. 2.

In this experiment the linear relation was observed, also, between $\triangle \mathrm{Si}$ and time. The apparent rate coefficients calculated by Eq. (1) are summarized in Table 5.

For the comparison of the results obtained under different experimental conditions, the values of silicon transfer rate per unit area of slag-metal interface at $1600^{\circ} \mathrm{C}$ are plotted against the ratio of interfacial areas $(r)$ in Fig. 9, where other investigators' results are also shown.

It is evident from the figure that the rate increases linearly with $r$ in the range $r<10$. The value of intercept of the line with the ordinate shows the contribution of the slag-metal interface on the rate and the slope of the line the effect of the slag-graphite interface. It was found that the value of the intercept was

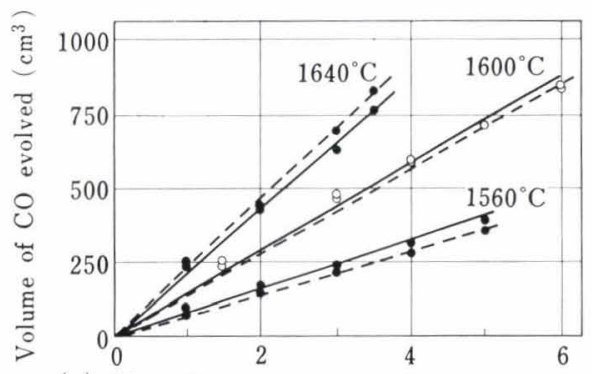

(a) Slag $F \quad$ Time $(\mathrm{hr})$

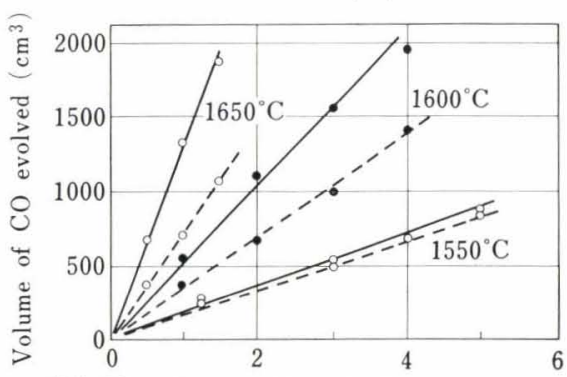

(b) Slag $A$ Time (hr)

Fig. 8. CO gas evolved during run

Broken line: calculated from silicon transferred

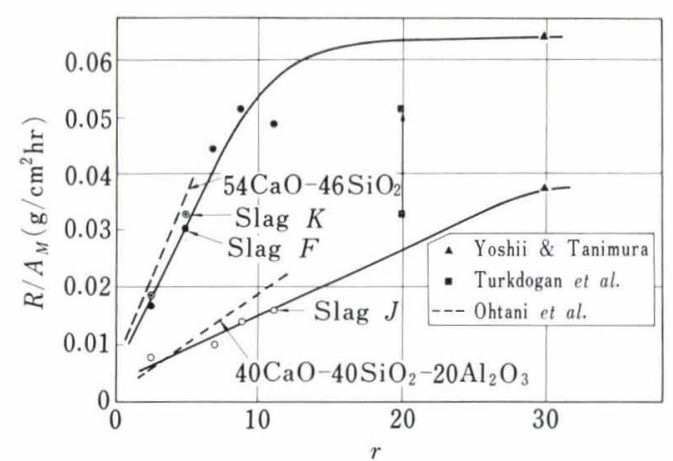

Fig. 9. Effect of the ratio of interfacial area on the rate of silicon transfer nearly equal to the slope for slag $F$ and $K$, while the slope was considerably small for slag $J$. This suggests that the effect of slag-graphite interface depends on slag composition. When the contribution of slaggraphite interface including the effect of surface roughness is represented by $\beta$, the empirical equation for the reduction rate of silica is

$$
\dot{n}_{\mathrm{Si}}=A_{M}(1+\beta \cdot r) k_{r} a_{\mathrm{SiO}_{2}},
$$

where $A_{M}$ is slag-metal interfacial area, $r$ the ratio of slag-graphite to slag-metal interfacial area and $k_{r}$ the rate constant.

Further, as shown in Fig. 9, the rate reaches a limiting value depending on slag composition at higher ratio of interfacial area.

\section{Effect of Atmosphere}

The atmosphere was an another point of the differences in experimental condition of the previous works, that is, some experiments were carried out in the $\mathrm{CO}$ atmosphere and others in the stream of argon. For the purpose of examining the effect of the atmosphere on the rate, argon in the place of $\mathrm{CO}$ was flushed onto the slag surface through a gas inlet tube at the rate of $50 \mathrm{cc} / \mathrm{min}$, but other experimental conditions were the same.

It was observed that the inner wall of graphite crucible was wetted by slag, while such a phenomenon was not observed in $\mathrm{CO}$ atmosphere. The relation between the weight of transferred silicon and time was also expressed by Eq. (1). Results are shown as plots of $R$ against $1 / T$ in Fig. 10, where the dotted lines show the results in $\mathrm{CO}$ atmosphere. The rate under an argon atmosphere increased about twice as that in CO atmosphere.

\section{Discussion}

\section{Rate-determining Step and Rate Equation}

The over-all reaction of reduction of silica in slag by carbon in liquid iron may be described by the following

Table 5. Rates of reduction at various ratios of interfacial area

\begin{tabular}{|c|c|c|c|c|c|c|}
\hline Slag & $\begin{array}{l}\text { Temp. } \\
\left({ }^{\circ} \mathrm{C}\right)\end{array}$ & $\begin{array}{c}\text { Metal } \\
(\mathrm{g})\end{array}$ & $\begin{array}{c}\text { Slag } \\
(\mathrm{g})\end{array}$ & $\begin{array}{l}\text { Slag-metal } \\
\text { interfacial } \\
\text { area }\left(\mathrm{cm}^{2}\right)\end{array}$ & $r$ & $\begin{array}{c}R \\
(\mathrm{~g} / \mathrm{hr})\end{array}$ \\
\hline \multirow{6}{*}{$F$} & 1620 & 100 & 40 & 4.9 & 5.0 & 0.186 \\
\hline & 1650 & 100 & 40 & 4.9 & 5.0 & 0.315 \\
\hline & 1570 & 100 & 40 & 4.9 & 5.0 & 0.093 \\
\hline & 1610 & 50 & 16.5 & 2.3 & 7.0 & 0.112 \\
\hline & 1620 & 50 & 22.2 & 2.3 & 9.0 & 0.142 \\
\hline & 1610 & 50 & 30.8 & 2.3 & 11.3 & 0.122 \\
\hline \multirow{3}{*}{$\kappa$} & 1530 & 100 & 40 & 4.9 & 5.0 & 0.083 \\
\hline & 1540 & 100 & 40 & 4.9 & 5.0 & 0.072 \\
\hline & 1620 & 100 & 40 & 4.9 & 5.0 & 0.193 \\
\hline \multirow{3}{*}{$J$} & 1655 & 50 & 16.5 & 2.3 & 7.0 & 0.040 \\
\hline & 1622 & 50 & 22.2 & 2.3 & 9.0 & 0.038 \\
\hline & 1605 & 50 & 30.8 & 2.3 & 11.3 & 0.037 \\
\hline
\end{tabular}




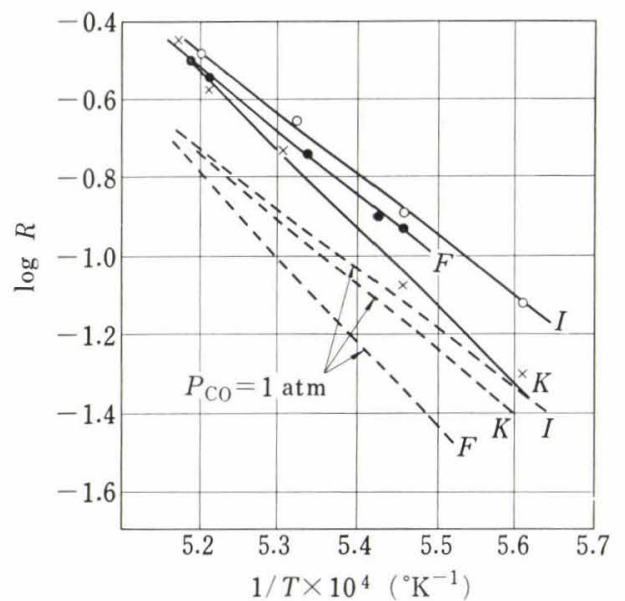

Fig. 10. Effect of temperature on the rate constant of run in argon

equation:

$$
\left(\mathrm{SiO}_{2}\right)+2 \underline{\mathrm{C}}=\underline{\mathrm{Si}}+2 \mathrm{CO}(\mathrm{g})
$$

but the reaction does not proceed as a trimolecular reaction at phase boundary. It would take place as a series of the following reactions:

$$
\begin{aligned}
& \left(\mathrm{SiO}_{2}\right) \longrightarrow \underline{\mathrm{Si}}+2 \underline{\mathrm{O}} \ldots \\
& 2 \underline{\mathrm{C}}+2 \underline{\mathrm{O}} \longrightarrow 2 \mathrm{CO}(\mathrm{g})
\end{aligned}
$$

or electrochemically as the simultaneous reaction of the following electrode reactions:

$$
\begin{aligned}
& \mathrm{Si}^{4+}+4 e \longrightarrow \underline{\mathrm{Si}} \ldots \ldots \ldots \ldots \ldots \ldots \\
& 2 \underline{\mathrm{C}}+2 \mathrm{O}^{2-} \longrightarrow 2 \mathrm{CO}(\mathrm{g})+4 e
\end{aligned}
$$

In the case where a graphite crucible is used, the following anodic reaction may occur at slag-graphite interface and influences on the silicon transfer rate.

$$
\mathrm{C} \text { (graphite) }+\mathrm{O}^{2-} \longrightarrow \mathrm{CO}(\mathrm{g})+2 e
$$

At any rate, the process of silicon transfer from slag to iron is a reaction between two phases and involves mass transport and interfacial chemical reaction steps. Hence, the over-all rate of silicon transfer is controlled by the slowest of these steps. At the present time it is not clear which step determines the reaction rate. To examine the rate-determining step, the rate equation derived assuming various steps as the rate-determining were compared with the experimental results.

If an interfacial reaction is the rate-determining step, it may be the decomposition of silica, because a large energy is necessary to breakdown $\mathrm{Si}-\mathrm{O}$ bonds. Then, the rate is given as follows:

$$
\dot{n}_{\mathrm{Si}}=A\left(\vec{k} \cdot a_{\mathrm{SiO}_{2}}-\overleftarrow{k} \cdot a_{\mathrm{Si}} \cdot a_{0}^{2}\right)
$$

where, $A$ is the interfacial area; $\vec{k}, \overleftarrow{k}$, forward and backward rate constants; $a$, the activity. The backward reaction can be ignored, because the silicon content during a run is considerably less than the equilibrium value with slag. Then, Eq. (10) may be simplified

$$
\dot{n}_{\mathrm{si}}=A \overrightarrow{k a_{\mathrm{SiO}_{2}}}
$$

According to Eq. (11), the weight of silicon transferred to iron increases linearly with time, if the change of slag composition during a run is negligible small, and the rate of reduction is proportional to the activity of silica. The results obtained in the present experiments are satisfied with this relation.

In the diffusion controlled reaction, the flux of species transferred across the slag-metal interface can be expressed by the product of mass transfer coefficient and driving force (concentration or activity difference). Thus, the transport process of such a species having the smallest product may be the rate-determining step. With respect to silica reduction two cases are considered, that is, the diffusion of oxygen in carbonsaturated iron on account of its low content and the diffusion of silicate anion in slag on account of its small mass transfer coefficient.

If the transport of oxygen from slag-metal interface to the site where $\mathrm{CO}$ gas is produced is the slowest step, the rate of silicon transfer is as follows given by Schuhmann ${ }^{8)}$ and others: $:^{2,4)}$

$$
\dot{n}_{\mathrm{Si}}=\frac{M_{\mathrm{Si}}}{2 M_{\mathrm{O}}} \dot{n}_{\mathrm{O}}=\frac{M_{\mathrm{Si}}}{2 M_{\mathrm{O}}} A k_{\mathrm{O}}\left(C_{\mathrm{O}}^{\mathrm{Si}}-C_{\mathrm{O}}^{\mathrm{C}}\right)
$$

where, $M$ is atomic weight; $k_{0}$, mass transfer coefficient of oxygen in liquid iron; $\mathrm{C}_{0}^{\mathrm{Si}}, \mathrm{C}_{\mathrm{O}}^{\mathrm{C}}$, oxygen contents in equilibrium with silicon and carbon in iron, respectively. The second term in the parenthesis may be ignored, since $\mathrm{C}_{0}^{\mathrm{Si}}>10 \mathrm{C}_{0}^{\mathrm{D}}$, then Eq. (12) is rewritten by introducing the equilibrium constant of reaction (5).

$$
\dot{n}_{\mathrm{Si}}=\text { const. } \times\left(a_{\mathrm{SiO}_{2}} / a_{\mathrm{Si}}\right)^{1 / 2}
$$

It is predicted from Eq. (13) that the rate decreases with time due to the increase of the activity of silicon and is proportional to one-half power of the activity of silica. These predictions do not coincide with the experimental results as shown in Figs. 3, 4, and 5.

If the diffusion of silicate anion is the slowest step, the rate can be expressed by the use of activity difference as driving force,

$$
\dot{n}_{\mathrm{Si}}=A k_{d}\left(a_{\mathrm{SiO}_{2}}-a_{\mathrm{SiO}_{2}}^{i}\right)
$$

where $k_{d}$ is mass transfer coefficient of silicon in liquid slag; $a_{\mathrm{SiO}_{2}}, a_{\mathrm{SiO}_{2}}^{i}$, activity of silica in slag bulk and at interface. The second term can be ignored because of low content of silicon in liquid iron. Equation (14) may be reduced to

$$
\dot{n}_{\mathrm{Si}}=A k_{d} a_{\mathrm{SiO}_{2}}
$$

which is the similar form to Eq. (11). However, $k_{d}$ depends not only on temperature, but also on flow condition of the system and physical properties of slag and is generally expressed as follows:

$$
k_{d}=\text { const. } D^{m} \cdot \eta^{-n}
$$

where $m$ and $n$ are constants determined by the flow 


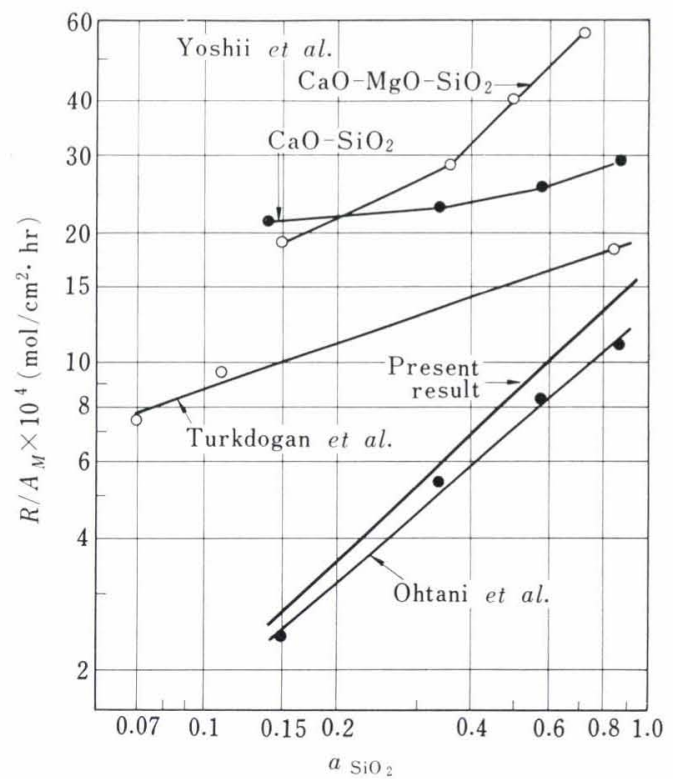

Fig. 11. Relation between rate constant of silica reduction and activity of silica for other worker's results

condition. The composition dependence of the diffusivity $D$ in slag is not clear due to few available data, but the product of the diffusivity $D$ and the viscosity $r$ may be considered to be constant. Accordingly, it may be estimated that the diffusivity of silicon in slag decreases at higher content of silica, because the viscosity of slag increases with the increase of silica content of slag. Therefore, it is regarded that a linear relation between the rate of silicon transfer and the activity of silica does not hold for Eq. (15).

The present results and the other workers' are illustrated as logarithmic plots of the flux of silicon transferred across slag-metal interface $v s$ 。 the activity of silica in Fig. 11. It is found that the slope of the line which corresponds to the reaction order is close to unity for the present results and Ohtani's ${ }^{6)}$ obtained from experiments at low ratio of interfacial area. But it is less than unity for experimental results at relatively high ratio such as Yoshii's ${ }^{3)}$ and Turkdogan's. ${ }^{2}$ From these consideration it is supposed that the rate-determining step is the interfacial reaction at low ratio of interfacial area, but it turns into the diffusion of silicate anion in slag at higher ratio.

\section{Electrochemical Consideration}

The effect of slag-graphite interface on the rate of reduction was not explained in the preceding discussions. The fact that the rate is promoted by the increase of slag-graphite interfacial area suggests that the reaction proceeds electrochemically. An electrochemical approach to kinetic study of silica reduction has been proposed by Ohtani et al., ${ }^{6)}$ but the rate equation was not given. Then, the derivation of the rate equation was attempted as stated in the followings.

In an electrochemical reaction such as $M^{z+}+z e \rightarrow$ $\underline{M}$, the reaction current $(I)$, that is, the reaction rate is related to the electrode potential $(E)$ as follows:

$$
I=z F A\left[k_{M^{z}+a_{M}+\exp (-\alpha z F E / R T)}\right.
$$

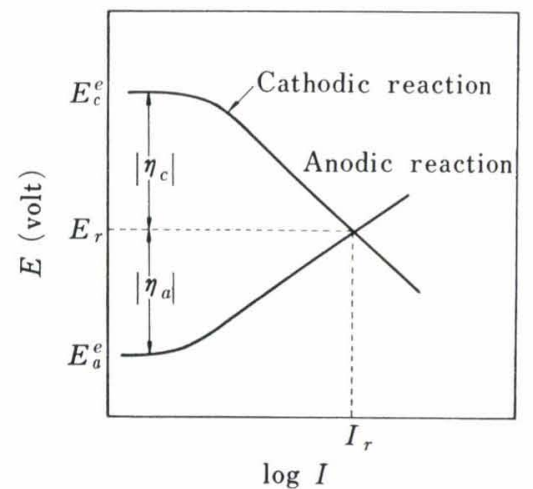

Fig. 12. Schematic diagram of the potential $(E)$-current (I) curves

$$
\begin{aligned}
& \left.-k_{M} a_{M} \exp \{(1-\alpha) z F E / R T\}\right] \\
= & A i_{o}[\exp (-\alpha z F \eta / R T) \\
& -\exp \{(1-\alpha) z F \eta / R T\}] \ldots \ldots . .
\end{aligned}
$$

where, $i_{0}$ : exchange current density

$$
\begin{aligned}
i_{o} & =z F k_{M^{z}} a_{M^{2}} \exp \left(-\alpha z F E^{e} / R T\right) \\
& =z F k_{M} a_{M} \exp \left\{(1-\alpha) z F E^{e} / R T\right\}
\end{aligned}
$$

$\gamma$ : overvoltage

$$
\eta=E-E^{e}
$$

$z$ : number of electron concerning reaction

F: Faraday's constant

$k_{M}^{z+}, k_{M}$ : rate constants of forward and backward reaction

$E^{e}:$ equilibrium electrode potential

$\alpha$ : constant, $0<a<1$.

In slag-metal reactions which take place spontaneously, there is no net flow of current.

$$
I_{c}+I_{a}=0 \ldots
$$

The difference between cathodic and anodic equilibrium electrode potentials must be equal to the sum of cathodic and anodic overvoltages, if there is no voltage drop other than due to reactions,

$$
\left|\eta_{e}\right|+\left|\eta_{a}\right|=\Delta E^{e}
$$

This implies that the reacting electrode potentials of cathode and anode are identical. When the potentialcurrent curves of cathodic and anodic reactions are as shown in Fig. 12, the reaction current and the reacting electrode potential are given by the intersect of two curves. The effect of slag composition and slaggraphite interface on the rate of silica reduction can be qualitatively explained by this concept. ${ }^{6)}$

If the potential-current curves of electrode reactions are known, the rate can be also calculated from them. In the present work, the rate-determining step is considered to be the interfacial reaction at low ratio of interfacial area as mentioned before, and it seems that the overvoltages of reactions (7) and (8) are so large that the backward reactions can be neglected. The cathodic reaction proceeds only at the slag-metal interface, hence the cathodic current $I_{c}$ is expressed

$$
I_{c}=z_{\mathrm{Si}} F A_{M} k_{\mathrm{Si}^{4}+} a_{\mathrm{Si}^{+}} \exp \left(-\alpha_{\mathrm{Si}} F E_{r} / R T\right)
$$

while the anodic reaction takes place at slag-metal and 
slag-graphite interfaces. If it is, for simplicity, assumed that the potential-current curves of reactions (8) and (9) are identical, the anodic current $I_{a}$ is

$$
\left.I_{a}=z_{c} F\left(A_{M}+A_{G}\right) k_{c} a_{c} a_{0^{2-}} \exp \left\{\left(1-\alpha_{c}\right) z_{c} F E_{r} / R T\right)\right\}
$$

where $A_{M}$ and $A_{G}$ are interfacial area of slag-metal and slag-graphite. Substituting Eqs. (22) and (23) into Eq. (20) and assuming $\alpha=1 / 2, z_{c}=2$, and $z_{\mathrm{si}}=4$, the reaction current may be expressed as follows:

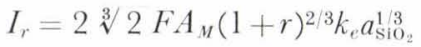

where

$$
k_{e}=k_{\mathrm{si}}^{1 / 3} \cdot k_{c}^{2 / 3}, \quad r=A_{G} / A_{M} .
$$

This equation qualitatively agrees with the present results.

In the preceding analysis the ions concerning the reaction were considered simply as $\mathrm{Si}^{4+}$ and $\mathrm{O}^{2-}$ because of the deficiency of our knowledge about ions in slag. These ions may be equilibrated with silica in slag,

$$
\mathrm{Si}^{4+}+2 \mathrm{O}^{2-}=\left(\mathrm{SiO}_{2}\right)
$$

By using this equation, reactions (7) and (8) are rewritten as follows:

$$
\begin{array}{ll}
\text { cathodic } & \left(\mathrm{SiO}_{2}\right)+4 e \longrightarrow \underline{\mathrm{Si}}+2 \mathrm{O}^{2-} \ldots \ldots \ldots . . \\
\text { anodic } & 2 \underline{\mathrm{C}}+\left(\mathrm{SiO}_{2}\right) \longrightarrow 2 \mathrm{CO}+\mathrm{Si}^{4+}+4 e .
\end{array}
$$

Based on these reaction formula, the reaction current was re-calculated,

$$
I_{r}=4 F A_{M}(1+r)^{1 / 2} k_{e}^{\prime} a_{\mathrm{SiO}_{2}}
$$

where

$$
k^{\prime}=k_{\mathrm{Si}}^{1 / 2} \cdot k_{c}^{1 / 2}
$$

Equation (28) agrees with results with respect to the effect of the activity of silica.

At present time, the calculation of the rate of reaction based on the electrochemical analysis is impossible because of only a few measurements on the potentialcurrent curve for slag-metal reaction at high temperature. But it is interesting that the appreciation to the observations is obtained by the electrochemical approach in spite of rough approximation.

The preceding discussion is limited in the range of low ratio of interfacial area. According to Eq. (28) the rate of reaction will be promoted due to the increase of anodic reaction area with increasing the ratio of interfacial area. But the rate of the supply of silicate anion to slag-metal interface has a limiting value, since the cathodic reaction area, namely, slag-metal interfacial area is constant. The rate of reaction reaches this limiting value with the increase of the ratio of interfacial area, and thereafter the rate will remain at this constant value regardless the increase of the ratio of interfacial area as shown in Fig. 10, because the rate of reaction is controlled by the diffusion of silicate anion in slag.

Then, the derivation of the rate equation valid over the wide range of the ratio of interfacial area was tried.
The rate of supply of silica to slag-metal interface may be given,

$$
\dot{n}_{\mathrm{Si}}=A_{M} k_{d}\left(a_{\mathrm{SiO}_{2}}-a_{\mathrm{SiO}_{2}}^{i}\right)
$$

Expressing the rate of interfacial reaction by the empirical equation instead of Eq. (28) because of lacking of data on the electrode reactions,

$$
\dot{n}_{\mathrm{Si}}=A_{M}(1+\beta \cdot r) k_{r} a_{\mathrm{SiO}_{2}}^{i}
$$

Both rates are identical at the steady state. Eliminating the unknown term at the interface from Eq. (12) and Eq. (29),

$$
\dot{n}_{\mathrm{Si}}=\frac{(1+\beta \cdot r) k_{r} \cdot k_{t}}{(1+\beta \cdot r) k_{r}+k_{d}} A_{M} a_{\mathrm{SiO}_{2}}
$$

When $r$ is small, $(1+\beta \cdot r) k_{r}$ can be neglected compared with $k_{r}$ and Eq. (30) reduces to Eq. (4) i.e. the rate of reaction is controlled by the interfacial reaction. When $r$ is sufficiently large, $k_{t}$ can be neglected i.e. the reaction becomes the diffusion controlled one.

\section{Effect of Temperature}

It was found that various values of apparent activation energies of silica reduction were reported by many investigators. For example, it was about 100 $\mathrm{kcal} / \mathrm{mol}$ in the present work and Ohtani's ${ }^{6)}$ experiments where the ratio of interfacial area were 2.5 and 1.5, respectively. While a small value, about 46 $\mathrm{kcal} / \mathrm{mol}$, was reported by Yoshii et al. ${ }^{3)}$ who measured at higher ratio $(r \doteqdot 30)$.

In studies on the reduction of solid silica by carbon in which the transfer process of silica in slag is absent, the activation energies of $90^{9)}$ and $117^{10)} \mathrm{kcal} / \mathrm{mol}$ were obtained. Since in these studies the rate-determining step is concluded to be chemical reaction, these values are regarded as the activation energy for the process of the breaking of $\mathrm{Si}-\mathrm{O}$ bond by carbon. It is one of the evidences for the silicon transfer being a chemical reaction control that the activation energy obtained in the present work is nearly equal to these values.

In the case where the reaction is controlled by the diffusion process, mass transfer coefficients are given by Eq. (16).

$$
k_{d}=\text { const. } \times D^{m} \cdot \eta^{-n}
$$

As the diffusivity and viscosity show the Arrhenius type dependence on temperature, the activation energy for the diffusion controlled reaction can be estimated from those for diffusion and viscous flow as follows:

$$
E_{r}=m E_{D}+n E_{\eta}
$$

where $E_{D}$ and $E_{\gamma_{j}}$ are the activation energies for diffusion and viscous flow, respectively. The activation energy obtained by Yoshii is close to that for viscous flow of slag, so in their experimental condition the reaction may be controlled by the diffusion of silicate anion in slag. The results of the effect of temperature on the rate of reaction also support the conclusion that the 
chemical reaction is the rate-determining step.

\section{Effect of Atmosphere}

As mentioned before, it was found that the rate of silica reduction under argon atmosphere is higher than that in $\mathrm{CO}$ atmosphere. In these experiments $\mathrm{CO}$ pressure in the furnace was low, 0.03 to $0.16 \mathrm{~atm}$ calculated from the evolution rate of $\mathrm{CO}$ gas.

Shchedrin ${ }^{11}$ ) who studied on the equilibrium between pig iron and blast furnace type slags under various pressures of carbon monoxide, reported that the activity of silica became larger at lower pressure of carbon monoxide. This suggests that the rate of reaction may be promoted under argon atmosphere.

Ohtani et al. ${ }^{6)}$ explained this increase of the rate of reaction from the electrochemical point of view, i.e. by the electrode potential shift to base side caused by the decrease of $\mathrm{CO}$ pressure. In the case where Tafel's relation holds, it may be predicted from Eq. (28) that the rate of the reduction does not depend on the partial pressure of carbon monoxide. Furthermore, the pressure of $\mathrm{CO}$ gas in the furnace is low, but that in $\mathrm{CO}$ gas bubble produced at slag-metal or slaggraphite interface is nearly equal to the total pressure of furnace. Therefore it comes into question which pressure is concerned with the reaction.

Furthermore, it was observed that the inner wall of graphite crucible was wetted by slag in the stream of argon. It may be predicted from this phenomenon that there is some change in physical properties of the slag. At present time, it is not clear for the reason why the rate of reaction increases under argon atmosphere.

\section{Conclusion}

The rate of reduction of silica in $\mathrm{CaO}-\mathrm{SiO}_{2}$ and $\mathrm{CaO}-\mathrm{Al}_{2} \mathrm{O}_{3}-\mathrm{SiO}_{2}$ slags by carbon in liquid iron was measured under various experimental conditions to examine the effects of slag composition, temperature, slag-graphite interface and atmosphere.

The results were as follows:

(1) The weight of silicon transferred into iron increased linearly with time as long as the change of slag composition during experiment could be ignored.

(2) The rate of reduction was proportional to the activity of silica over the whole composition range of slag in the present experiment.

(3) The rate of reduction increased with the increase of the ratio of slag-graphite to slag-metal interfacial area.

(4) The apparent activation energies were about $100 \mathrm{kcal} / \mathrm{mol}$ for binary slags and slightly varied from 70 to $85 \mathrm{kcal} / \mathrm{mol}$ for ternary slags.

(5) The rate of reduction in an argon atmosphere was twice as fast as that in $\mathrm{CO}$ atmosphere.

From these results it was concluded that the reaction proceeded electrochemically, and the interfacial chemical reaction was the rate-determining step under the present experimental conditions. The rate equation was expressed as follows:

$$
\dot{n}_{\mathrm{Si}}=A_{M}(1+\beta \cdot r) k_{r} a_{\mathrm{SiO}_{2}}
$$

\section{REFERENCES}

1) J. C. Futon and J. Chipman: Trans. Met. Soc. AIME, 215 (1959), 888.

2) E. T. Turkdogan, P. Grievson, and J. F. Beisler: Trans. Met. Soc. AIME, 227 (1963), 1265.

3) T. Yoshii and T. Tanimura: Tetsu-to-Hagané, 51 (1965), $833 ; 1823 ; 52$ (1966), 1448.

4) J. R. Rawling and J. F. Elliott: Trans. Met. Soc. AIME, 233 (1965), 1539

5) M. Grimble, R. G. Ward, and J. William: J. Iron Steel Inst., 203 (1965), 264.

6) M. Ashizuka, M. Tokuda, and M. Ohtani: Tetsu-to-Hagané, 54 (1968), 1437; 1447.

7) R. H. Rein and J. Chipman: Trans. Met. Soc. AIME, 233 (1965), 415.

8) R. Schuhmann: Trans. Met. Soc. AIME, 218 (1960), 1130.

9) Y. Kawai, K. Mori, and M. Iguchi: Tetsu-to-Hagané, 54 (1968), 261.

10) N. Klinger, E. L. Strauss, and K. L. Komarek: J. Amer. Ceram. Soc., 49 (1966), 369.

11) V. M. Shchedrin: Izv. Akad. Nauk SSSR, OTN, 1962 (No. 1), 23. 